\title{
Conhecimento local sobre a importância de um reflorestamento ciliar para a conservação ambiental do Alto São Francisco, Minas Gerais
}

\author{
Flávia Peres Nunes ${ }^{1,3}$ \& Maria Tereza Cândido Pinto ${ }^{2}$ \\ Biota Neotropica v7 (n3) - http://www.biotaneotropica.org.br/v7n3/pt/abstract?article+bn03307032007 \\ Recebido em 12/06/07 \\ Versão reformulada recebida em 07/10/07 \\ Publicado em 18/10/07 \\ ${ }^{1}$ Pós-graduação em Ecologia, Conservação e Manejo da Vida Silvestre, \\ Instituto de Ciências Biológicas - ICB, \\ Universidade Federal de Minas Gerais - UFMG, Av. Antônio Carlos, 6627, \\ Pampulha, CEP 31270-901, Belo Horizonte, MG, Brasil, http://www.icb.ufmg.br/ \\ ${ }^{2}$ Instituto de Ciências Biológicas e da Saúde, PUC Minas, Av. Dom José Gaspar, 500, \\ Coração Eucarístico, Belo Horizonte, MG, Brasil, http://www.pucminas.br/ \\ ${ }^{3}$ Autor para correspondência: Flávia Peres Nunes, e-mail: flaviaperesnunes@yahoo.com.br
}

\begin{abstract}
Nunes, F.P. \& Pinto, M.T.C. Local knowledge about the importance of the reforested gallery forest in the environmental conservation of the upper Rio São Francisco, Minas Gerais. Biota Neotrop. Sep/Dez 2007 vol.7, no. 3 http://www.biotaneotropica.org.br/v7n3/pt/abstract?article+bn03307032007. ISSN 1676-0603.

The aim of this study was to recoup, together with professional fisherman $(\mathrm{N}=10)$ and environmentalists $(\mathrm{N}=10)$, empirical knowledge concerning the importance of the reforestation of the riparian zone in the upper Rio São Francisco region, in Minas Gerais state. Such reforestation is vital for maintaining the environmental integrity of the river. Working groups were selected based on an initial contact, made expressly in order to choose participating members. These members were submitted to semi-structured questionnaires with several questions regarding the importance of preserving riparian vegetation. Interviews were conducted from October/2001 to February/2002. Although interviews revealed distinct social profiles, especially with respect to level of formal education received by participants and their different reasons for coexisting with the gallery forest of the region, both groups recognized, equally, the importance of the riparian vegetation, both native and reforested, in preserving the environmental quality of the surrounding aquatic ecosystem. Such perception has been motivated by the work of local NGO's in raising environmental awareness in the different social segments of the municipalities population involved. By maintaining a permanent coexistence with the surrounding gallery forest, both groups displayed an ecological understanding which overlapped with current scientific knowledge, revealing a rich source of information from which to improve preservation and recuperation strategies of the region riparian vegetation.
\end{abstract}

Keywords: riparian reforestation, local knowledge, professional fisherman, environmentalists, São Francisco River.

\section{Resumo}

Nunes, F.P. \& Pinto, M.T.C. Conhecimento local sobre a importância de um reflorestamento ciliar para a conservação ambiental do Alto São Francisco, Minas Gerais. Biota Neotrop. Sep/Dez 2007 vol. 7, no. 3 http://www.biotaneotropica.org.br/v7n3/pt/abstract?article+bn03307032007. ISSN 1676-0603.

O objetivo deste trabalho foi resgatar junto a um grupo de pescadores profissionais $(\mathrm{N}=10)$ e ambientalistas ( $\mathrm{N}=10)$ na região do Alto São Francisco, no estado de Minas Gerais, o conhecimento empírico sobre a importância de um reflorestamento ciliar para a manutenção da integridade ambiental do rio São Francisco. Os grupos foram selecionados a partir de um contato inicial para a escolha dos membros participantes e, posteriormente, submetidos a questionários semi-estruturados com questões variadas sobre o tema abordado. As entrevistas ocorreram no período de outubro/2001 a fevereiro/2002. Embora revelassem perfis sociais distintos, especialmente no tocante à formação escolar e diferente motivação para o convívio com as matas ciliares da região, os dois grupos reconheceram a importância da vegetação ribeirinha, nativa e reflorestada, para a preservação da qualidade ambiental dos ecossistemas aquáticos da bacia hidrográfica do rio São Francisco. Tal percepção foi motivada pelo trabalho de conscientização ambientalista das ONGs locais junto aos diferentes segmentos sociais da população dos municípios envolvidos. Ao manterem um convívio permanente com as matas ciliares, os dois grupos demonstraram percepções que se sobrepuseram à literatura técnico-científica, revelando-se uma fonte rica de informações para o aprimoramento das estratégias de preservação e recuperação da vegetação ribeirinha da região.

Palavras-chave: reflorestamento ciliar, conhecimento local, pescadores profissionais, ambientalistas, rio São Francisco. 


\section{Introdução}

O manejo e a recuperação das matas ciliares foi incluído no Programa das Nações Unidas para o Meio Ambiente (PNUMA) pela importância destas formações vegetais para a conservação da biodiversidade e a manutenção do equilíbrio dos ecossistemas em todo o planeta (Barbosa 2000). O sucesso de um projeto de restauração e conservação de matas ciliares deve levar em conta o conhecimento do ambiente físico, biológico e humano (Kageyama \& Gandara 2000). Neste contexto, são de grande interesse as informações sobre o solo, hidrologia, relevo, remanescentes da vegetação nativa, uso da terra, histórico da ocupação humana e o conhecimento empírico local. Apesar disso, estudos que contemplam a região de interface terraágua e o homem de uma determinada região ainda hoje são escassos, embora sejam urgentes, especialmente em áreas tropicais, onde as populações nativas são objeto de pressão de aculturamento por parte da sociedade dominante (Amorozo \& Gély 1998).

São inúmeras as relações mantidas entre a região ribeirinha e o ambiente aquático (Gooley et al. 1978, Gorgônio 1998, Barbosa 2000, Barrela et al. 2000, Kageyama \& Gandara 2000, Martins 2001, Henry 2003, Lima 2003), como o fornecimento direto pelas copas das árvores de frutos, sementes e flores, usados como alimento pelos peixes, sombreamento, manutenção da temperatura da água e a proteção do corpo hídrico contra o assoreamento das margens e do solo do entorno. Estas interrelações são verificadas em todos os ambientes da região de interface terra-água, cujas matas ciliares sejam preservadas, inclusive nas planícies de inundação, como a localizada no alto da bacia hidrográfica do rio São Francisco, no estado de Minas Gerais. Em ecossistemas deste tipo, sujeitos a pulsos periódicos de inundação e de alta produtividade biológica (Mitsch \& Gosselink 1993), estudos que relacionem aspectos físicos, biológicos e humanos são de grande importância para definir formas de manejo ambiental adequadas aos seus compartimentos terrestres e aquáticos. Dessa maneira, as matas ciliares têm papel decisivo nestes ambientes, por se localizarem na região de interface terra-água, influenciando tanto a porção terrestre quanto a aquática do sistema (Mitsch \& Gosselink 1993). Sua manutenção é, portanto, pré-requisito para a preservação do rio e do solo do entorno, assim como para o fornecimento de frutos, água e de peixes à população humana que usa estes recursos.

O processo de degradação das formações ciliares no estado de Minas Gerais, além de desrespeitar a legislação vigente (Código Florestal de Minas Gerais - Lei N. ${ }^{\circ}$ 4.777/65) que obriga a sua preservação, resulta em inúmeros problemas ambientais, como o surgimento de processos erosivos no solo marginal e o assoreamento dos cursos d'água. Para interromper o cenário de degradação do ambiente ciliar e obter o sucesso esperado em planos de manejo e recuperação dessas formações vegetais, é necessário considerar as relações existentes entre os sistemas terrestres e aquáticos e a população humana que convive com eles.

No Brasil, nos últimos anos, dada a crescente conscientização da comunidade civil e científica sobre a necessidade da conservação dos recursos naturais e a legislação vigente que obriga a recuperação de áreas degradadas, tem sido constatado grande avanço na pesquisa científica para a implementação de projetos de reflorestamentos de ambientes ciliares. Especialmente para o estado de Minas Gerais, grandes empresas privadas e estatais do setor energético têm contribuído para o desenvolvimento de metodologias de recuperação de matas ciliares, principalmente através de projetos de revegetação das margens de reservatórios de suas usinas hidrelétricas (Martins 2001). Contudo, estudos de recuperação de matas ciliares localizadas ao longo do curso dos rios que formam as grandes bacias hidrográficas do estado, a exemplo do rio São Francisco, ainda hoje são escassos.
Nesse contexto, o presente trabalho teve como objetivo resgatar o conhecimento local de dois grupos sociais distintos, pescadores e ambientalistas residentes no município de Lagoa da Prata, no estado de Minas Gerais, sobre o papel de um reflorestamento ciliar marginal a um tributário do rio São Francisco, para a manutenção da integridade do rio e de sua ictiofauna, comparando-o ao conhecimento científico correlato.

\section{Material e Métodos}

\section{1. Área de estudo}

O município de Lagoa da Prata está localizado na região do Alto São Francisco no estado de Minas Gerais (Figura 1), a 300 km das nascentes do rio São Francisco (Brasil 1975), em seu trajeto pela Depressão Sanfransciscana (CETEC 1983). Na região de Lagoa da Prata, o sistema fluvial é representado por um segmento meândrico do rio São Francisco e por inúmeras lagoas marginais situadas nos limites internos do município, além de diversos tributários, incluindose entre eles o rio Santana, um de seus importantes afluentes pela margem direita (Brasil 1975).

Chama a atenção a intensa atuação antrópica exercida na região, percebida através da substituição do cerrado (vegetação nativa) e das espécies vegetais arbustivas e arbóreas das matas capoeiras, por gramíneas para pastagens e espécies de lavouras temporárias que, ao serem introduzidas, terminaram por mudar a paisagem local (Le Sann 2002). Dentre as espécies cultivadas, destaca-se a cana-deaçúcar, principal produto agrícola do município, cuja área cultivada ocupa 5.800 hectares. Tais culturas, principalmente a canavieira, foram responsáveis pela alteração da cobertura vegetal do solo, especialmente às margens dos rios, local considerado ideal pelos agricultores para o plantio das lavouras, o que resultou no extenso desmatamento da vegetação ciliar, como verificado ao longo do rio São Francisco e tributários. Em conseqüência, faixas estreitas e descontínuas de mata ciliar nativa secundária acompanham o curso do rio e tributários, delimitando entre si grandes extensões de solo desnudo, propenso à erosão.

Precipitações mensais com valores que oscilam entre zero e $500 \mathrm{~mm}$, totais anuais de aproximadamente $1500 \mathrm{~mm}$ e temperaturas médias de $25{ }^{\circ} \mathrm{C}$, permitem que se classifique o clima da região no tipo Cwa/Aw de Köeppen, caracterizado como tropical com verão úmido e inverno seco (CETEC, 1983).

Fundada em 1875 e com uma população atual de 38.737 habitantes (Le Sann 2002), apesar de seu pequeno porte, Lagoa da Prata se sobressai entre os municípios vizinhos pela organização de sua sociedade civil, retratada, especialmente, pela ação de diversas organizações não governamentais (ONGs) ambientalistas que contribuíram de forma significativa para o engajamento da população do município nas questões conservacionistas da região. As atividades desses grupos, lideradas pelas ONGs locais com destaque para a Associação Ambientalista do Alto São Francisco/AASF e Associação Ambientalista de Pescadores Amadores/AAPA, em conjunto com o poder público municipal, contemplam diversos setores da sociedade, representados pela comunidade escolar, pescadores profissionais e amadores, produtores rurais, entre outros. Tal estratégia de ação culminou no ano de 1999, com a inclusão do município no "Guinnes Book”, por representar na época, a cidade capaz de efetuar o maior plantio de mudas de mata ciliar, em um único evento. Desde então, a revegetação de matas ribeirinhas do rio São Francisco, tributários e lagoas marginais, tem sido executada sistematicamente na região, para garantir a preservação da qualidade ambiental dos corpos d'água e a manutenção de seus recursos pesqueiros neste trecho da bacia. 


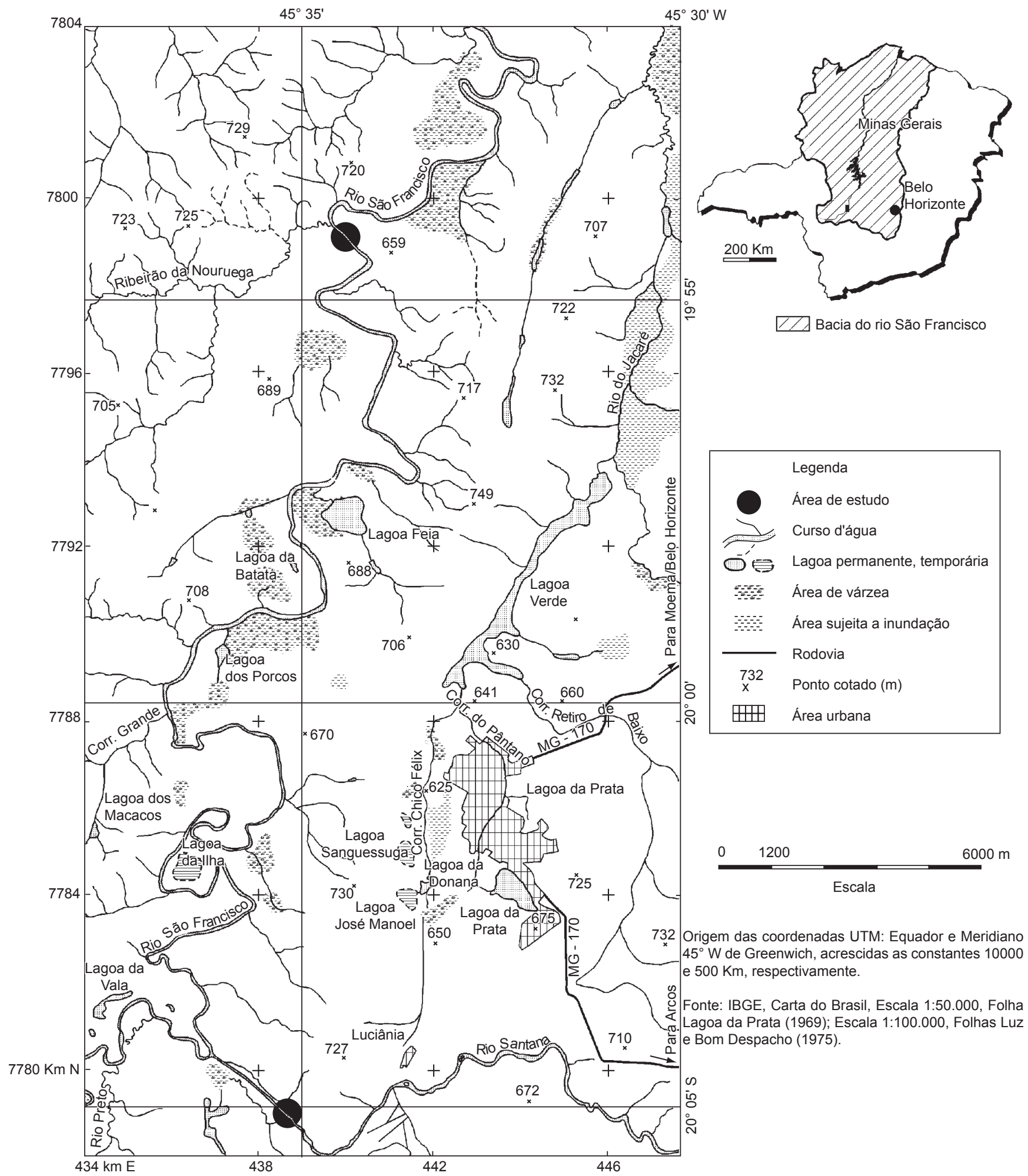

Figura 1. Áreas de estudo no alto rio São Francisco, estado de Minas Gerais.

Figure 1. Study areas on the upper São Francisco river, Minas Gerais State.

Com o intuito de comparar o conhecimento local ao conhecimento científico existente para a área de estudo, foram compilados dados de estudos realizados em 2 faixas de matas ciliares do local: o Reflorestamento da Fazenda Capoeira da Cana (12,5 ha), representado por um plantio de espécies arbustivas e arbóreas situado à aproximadamente
$2 \mathrm{~m}$ da margem do rio Santana $\left(20^{\circ} 05^{\prime} \mathrm{S}\right.$ e $\left.45^{\circ} 35^{\prime} \mathrm{W}\right)$, à $2,5 \mathrm{~km}$ de sua confluência com o rio São Francisco e a Mata do Urubu (11,0 ha; mata testemunho), representada por uma faixa de mata ciliar nativa, secundária, localizada às margens do rio São Francisco (19 54' S e $45^{\circ} 33^{\prime}$ W; Figura 1), distantes entre si 40 km (Barreto 2002). Dessa 
forma, a dinâmica de funcionamento das matas ciliares foi avaliada por meio da quantificação da serapilheira produzida descrita no estudo de Nunes (2005) e a estrutura por meio da composição florística e dos seus valores de riqueza e diversidade apresentados no trabalho de Barreto (2002).

O Reflorestamento da Fazenda Capoeira da Cana conteve predominantemente espécies frutíferas, tais como amoreira (Morus nigra), e exóticas como unha-de-vaca (Bauhinia variegata) e leucena (Leucaena leucocephala), (Tabela 1). Leucena foi a espécie que mais se destacou, com alta densidade relativa (30\%) e índice de valor de importância (30,2\%). A Mata do Urubu foi composta por espécies características de mata ciliar secundária em estágio avançado de regeneração e por espécies clímax da região (Barreto 2002). Nesta mata, as espécies de maior densidade relativa foram canela de cutia (Trichilia clausseni; 20\%), seguida de mamoneira (Alchornea sp.; 17,5\%) e pitanga (Eugenia sp.; 6,25\%).

Embora a Mata do Urubu tenha apresentado 26 espécies vegetais, o que lhe conferiu maior riqueza em relação ao Reflorestamento da Fazenda Capoeira da Cana (Tabela 1), que apresentou 17 espécies, a comparação dos valores de diversidade (Indice de Shanonn) revelou para ambas as matas resultados semelhantes (Mata do Urubu; $\mathrm{H}^{\prime}=2,71$; Reflorestamento; H'=2,37). A produção total de serapilheira (Figura 2) foi elevada em ambas as matas $\left(15,1 \mathrm{t} \mathrm{ha}^{-1} /\right.$ ano na mata nativa e 11,4 t ha-1/ano no reflorestamento). As folhas contribuíram com o maior percentual para a biomassa total $(67,5 \%$ na Mata do Urubu e $69,4 \%$ no Reflorestamento) seguidas dos ramos (19,1\% na
Tabela 1. Espécies do Reflorestamento e da Mata do Urubu, segundo Barreto (2002).

Table 1. Species of the Reforestation and Mata do Urubu, according to Barreto (2002).

\begin{tabular}{|c|c|c|}
\hline Família & Nome Científico & Nome Popular \\
\hline \multirow{2}{*}{ Anacardiaceae } & Mangifera indica ${ }^{1}$ & Mangueira \\
\hline & Schinus terebinthifolius ${ }^{\mathrm{a}}$ & Aroeirinha \\
\hline \multirow[t]{2}{*}{ Bignoniaceae } & Tabebuia rosea ${ }^{\mathrm{a}}$ & Ipê-branco \\
\hline & Tabebuia serratifolia ${ }^{1}$ & Ipê-amarelo \\
\hline Bombacaceae & Chorisia speciosa $^{1}$ & Paineira \\
\hline Euphorbiaceae & Croton urucurana ${ }^{1}$ & Sangra-d'água \\
\hline \multirow[t]{8}{*}{ Fabaceae } & Anadenanthera peregrina ${ }^{\mathrm{a}}$ & Angico \\
\hline & Bauhinia variegata ${ }^{1}$ & Unha-de-vaca \\
\hline & Caesalphinia ferrea $a^{1,2}$ & Pau-ferro \\
\hline & Deguelia costata $^{\mathrm{a}}$ & Pau-de-carrapato \\
\hline & Enterolobium contortisiliquum ${ }^{\mathrm{a}}$ & Tamboril \\
\hline & Hymenaea courbaril ${ }^{2}$ & Jatobá \\
\hline & Inga capitata $^{\mathrm{a}}$ & Ingazeiro \\
\hline & Leucena leucocephala ${ }^{1}$ & Leucena \\
\hline Meliaceae & Melia azedarach ${ }^{1}$ & Santa-bárbara \\
\hline Moraceae & Morus nigra ${ }^{1}$ & Amoreira \\
\hline Myrtaceae & $P_{\text {sidium guajava }}{ }^{1}$ & Goiabeira \\
\hline
\end{tabular}

${ }^{1}$ Espécies plantadas no Reflorestamento; ${ }^{2}$ Espécies presentes no Reflorestamento e na Mata do Urubu; 'Espécies novas.

${ }^{1}$ Species planted in the Reforestation; ${ }^{2}$ Species present in the Reforestation and Mata do Urubu; ${ }^{\mathrm{N}} \mathrm{New}$ species.
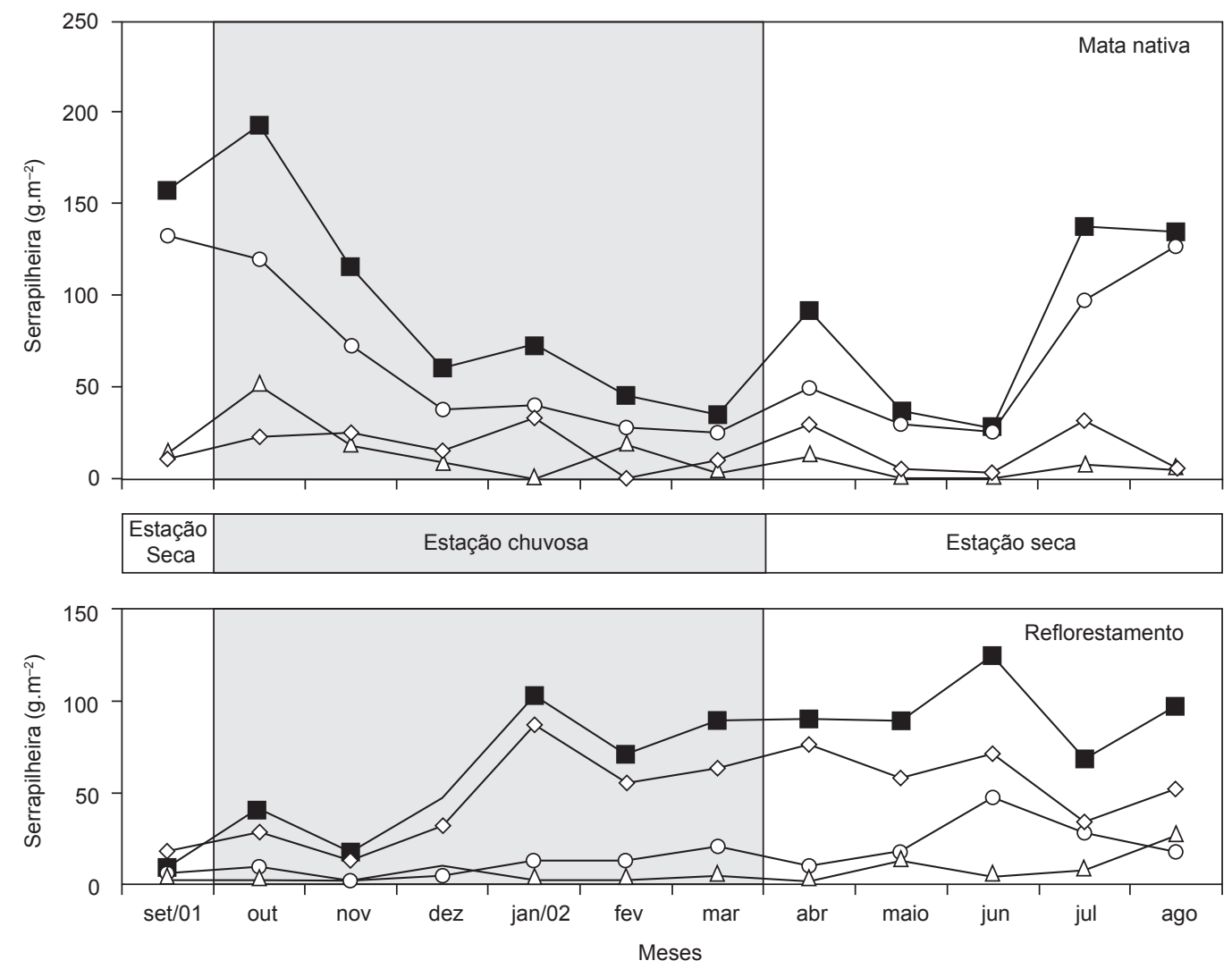

$$
\multimap \text { Folhas } \leadsto \text { Ramos } \leadsto \text { Flores + frutos }
$$

Figura 2. Produção de serapilheira no Reflorestamento da Fazenda Capoeira da Cana (a) e Mata do Urubu (b).

Figure 2. Litterfall in Reflorestamento da Fazenda Capoeira da Cana (a) and Mata do Urubu (b). 
Mata do Urubu e 23,2\% no Reflorestamento) e dos órgãos de reprodução (13,4\% na Mata do Urubu e 7,4\% no Reflorestamento).

A sazonalidade da produção de serapilheira foi verificada somente na mata nativa, através do despejo maciço de órgãos ao solo durante a estação seca. No reflorestamento, tal fato não se verificou, uma vez que os maiores valores de biomassa total, liderados pelas folhas, foram obtidos tanto na estação chuvosa como na seca (Nunes, 2005).

\section{Procedimentos}

Para o desenvolvimento da pesquisa, foram escolhidos dois grupos sociais distintos, a saber: o dos "pescadores" e o dos "ambientalistas", que foram selecionados entre os moradores do município de Lagoa da Prata, por apresentarem um convívio constante com o ambiente ribeirinho. $\mathrm{O}$ grupo dos pescadores foi formado por pessoas que praticassem pesca profissional, enquanto o dos ambientalistas conteve somente indivíduos que exerciam atividades coordenadas pelas ONGs ambientalistas do município. Para a obtenção dos dados, foram realizadas 5 visitas à campo, com duração de 3 dias por visita, entre outubro de 2001 e fevereiro de 2002.

Inicialmente, foi feito um primeiro contato junto aos grupos para definição do número amostral. Cada grupo foi formado por 10 indivíduos, como proposto por Gladwin (1989), que sugere um modelo com 10 participantes no mínimo, levando-se em conta a complexidade do problema estudado e a experiência do pesquisador (Seidl citado em Gladwin 1989). Este primeiro contato foi caracterizado por um diálogo informal e individual, de forma a permitir a delimitação do problema estudado e a obtenção de informações a serem coletadas por meio da identificação de casos representativos e das pessoas envolvidas a serem consideradas no trabalho, como proposto por Richardson (1999). Posteriormente, os membros de cada grupo foram submetidos à aplicação de entrevistas semi-estruturadas, compostas por questões fixas, mas com a liberdade de serem redefinidas pelo pesquisador, permitindo-lhe direcionar o diálogo para as questões a serem investigadas (Viertler 2002). Os itens abordados levaram em conta a estrutura e função da vegetação ciliar reflorestada, bem como a importância de sua preservação para a manutenção da ictiofauna local, cujos resultados foram comparados com os da vegetação nativa, utilizada no presente trabalho como referencial de comparação (mata testemunho). O conhecimento local obtido foi comparado ao conhecimento científico existente para os dois trechos de matas ciliares, caracterizados anteriormente no item Área de estudo.

\section{Resultados}

Com idade média de 57 anos, os pescadores nascidos em Lagoa da Prata apresentaram baixo nível de escolaridade, a maioria tendo cursado apenas o ensino básico, havendo entre eles, inclusive, analfabetos. Todos eram casados e tiveram em média 4,8 filhos. Os ambientalistas foram representados por indivíduos mais jovens cuja média etária da maioria do grupo (70\%) oscilou em torno de 41 anos. Todos nasceram em Lagoa da Prata e tiveram um número menor de filhos (2, em média) que os pescadores. O nível de escolaridade do grupo foi mais alto que o dos pescadores, com a maioria deles tendo cursado o ensino médio ou até mesmo o ensino superior (30\%).

Ambos os grupos conheciam a Mata do Urubu marginal ao rio São Francisco e o Reflorestamento da Fazenda Capoeira da Cana localizado às margens do rio Santana. Para os pescadores, o contato com as matas era obrigatório, determinado pela necessidade de atravessá-las na sua rota até o rio, onde pescavam, enquanto que para os ambientalistas o contato foi voluntário (Tabela 2). Embora os pescadores se contactassem com as matas por "dever de profissão" (para a pesca), eles também as visitaram em busca de lazer ou para "fiscalizar o
Tabela 2. Motivo de contato dos ambientalistas e pescadores com as matas ciliares da região de Lagoa da Prata.

Table 2. Reason of contact between environmentalists and fishermen with the riparian vegetation of the region of Lagoa da Prata.

\begin{tabular}{lcc}
\hline \multicolumn{1}{c}{ Motivo } & Pescadores (\%) & Ambientalistas (\%) \\
\hline Lazer & 10 & 60 \\
Realizar trabalhos & 0 & 40 \\
Fiscalização & 30 & 50 \\
Lazer e fiscalização & 20 & 80 \\
Coleta de sementes & 0 & 30 \\
Plantio de árvores & 10 & 10 \\
Rota de deslocamento & 100 & 10 \\
\hline
\end{tabular}

estado de conservação da vegetação". Parte dos ambientalistas foi também "catalogar espécies vegetais" e "realizar estudos em grupos" entendidos por eles como realizar trabalhos. Somente uma minoria dos dois grupos esteve nas matas para plantar árvores.

Apesar do contato mantido com a mata nativa (Mata do Urubu) e o Reflorestamento da Fazenda Capoeira da Cana, ambientalistas e pescadores, através das respostas fornecidas no questionário sobre as dimensões necessárias a um reflorestamento ciliar, demonstraram desconhecer as dimensões mínimas exigidas por lei para que uma faixa de vegetação ciliar mantenha a integridade do rio e do solo das margens, no qual está inserida (Tabela 3).

A maioria dos grupos, entretanto, não concordou com a localização do reflorestamento às margens do rio Santana, dizendo que a distância da margem não está correta, afirmando que o reflorestamento foi plantado distante da margem do rio, o que o impede de proteger o ambiente aquático. Somente uma parte dos grupos não concordou com as espécies usadas no seu plantio, por considerá-las inadequadas, uma vez que elas não eram nativas da região. A totalidade dos ambientalistas e metade dos pescadores reconheceu uma mudança na composição florística do reflorestamento. Tal fato poderia ser explicado pela participação de todos os ambientalistas entrevistados no plantio das mudas, enquanto que apenas uma pequena parte dos pescadores se envolveu com este tipo de tarefa.

Ambos os grupos identificaram a estação da seca como a época de maior despejo ao solo de folhas, flores e frutos, tanto pelo Reflorestamento quanto pela Mata do Urubu (Tabela 4). Para eles, a biomassa vegetal (serapilheira) serve de adubo (húmus) para o solo ou de alimento para os animais terrestres, tais como aves e pequenos mamíferos que freqüentam a região ribeirinha em busca de água e alimento. Os grupos afirmaram também que a serapilheira serve de alimento para os peixes, apesar de não identificarem a existência de uma relação entre o período de maior despejo de flores e frutos pela vegetação ciliar e o aumento do número de peixes nos rios.

A Tabela 5 apresenta a percepção dos pescadores e ambientalistas sobre os fatores que determinam a importância da mata ciliar nativa e reflorestada para os rios Santana e São Francisco, respectivamente, e o ambiente terrestre do entorno. Ambos os grupos atribuíram à mata nativa e ao reflorestamento a capacidade de fornecer alimento, abrigo e proteção à fauna aquática, reter resíduos que caem no rio e proteger o solo da margem contra erosão e assoreamento do rio, afirmando que a vegetação ciliar "protege a barranca do rio", "evita assoreamento", "controla a temperatura da água", "dá sombra", "faz voltar as águas" e "dá alimento para os peixes". Tais afirmativas tiveram como justificativa o fato de que os peixes procuram os locais do rio onde há vegetação ciliar, atraídos pela sombra, alimento e abrigo que as copas das árvores fornecem ao rio, não importando para isto se o solo marginal está recoberto por 
Tabela 3. Dimensões, localização e composição florística do Reflorestamento da Fazenda Capoeira da Cana, segundo a percepção dos pescadores e ambientalistas.

Table 3. Size, localization and floristic composition of the Reflorestamento da Fazenda Capoeira da Cana, according to perception of fishermen and environmentalists.

\begin{tabular}{|c|c|c|c|c|c|c|}
\hline \multirow{2}{*}{$\begin{array}{l}\text { Características do } \\
\text { Reflorestamento }\end{array}$} & \multicolumn{3}{|c|}{ Pescadores (\%) } & \multicolumn{3}{|c|}{ Ambientalistas (\%) } \\
\hline & Adequado & Inadequado & Não sei & Adequado & Inadequado & Não sei \\
\hline Comprimento & 40 & 30 & 30 & 10 & 80 & 10 \\
\hline Largura & 40 & 30 & 30 & 30 & 70 & 0 \\
\hline Distância da margem & 20 & 60 & 20 & 30 & 60 & 10 \\
\hline Espécies usadas no plantio & 10 & 50 & 40 & 30 & 40 & 30 \\
\hline $\begin{array}{l}\text { Mudança na composição florística, } \\
\text { entre a época do plantio e a atual }\end{array}$ & 50 & 40 & 10 & 100 & 0 & - \\
\hline
\end{tabular}

Tabela 4. Conhecimento dos pescadores e ambientalistas sobre a produção e o destino da serapilheira da Mata do Urubu e do Reflorestamento da Fazenda da Capoeira da Cana.

Table 4. Knowledge of fishermen and environmentalists about litter production and destination in the Mata do Urubu and in the Reflorestamento da Fazenda Capoeira da Cana.

\begin{tabular}{|c|c|c|c|c|c|}
\hline \multirow[t]{2}{*}{ Processo/Destino } & \multirow[t]{2}{*}{ Período do ano } & \multicolumn{2}{|c|}{ Pescadores (\%) } & \multicolumn{2}{|c|}{ Ambientalistas (\%) } \\
\hline & & $\mathbf{M U}$ & RFCC & MU & RFCC \\
\hline \multicolumn{6}{|l|}{ I- Produção de serapilheira } \\
\hline \multirow[t]{3}{*}{ Folha } & Estação seca & 90 & 90 & 100 & 100 \\
\hline & Estação chuvosa & 0 & 0 & 0 & 0 \\
\hline & O ano todo & 10 & 10 & 0 & 0 \\
\hline \multirow[t]{3}{*}{ Flor/fruto } & Estação seca & 100 & 70 & 100 & 90 \\
\hline & Estação chuvosa & 0 & 10 & 0 & 0 \\
\hline & O ano todo & 0 & 20 & 0 & 10 \\
\hline \multicolumn{6}{|l|}{ II- Destino da Serapilheira } \\
\hline Adubo para o solo/húmus & & \multicolumn{2}{|c|}{60} & \multicolumn{2}{|c|}{70} \\
\hline Alimento para animal terrestre e peixes & & \multicolumn{2}{|c|}{40} & \multicolumn{2}{|c|}{30} \\
\hline
\end{tabular}

Tabela 5. Benefícios atribuídos aos rios pela mata nativa e o reflorestamento segundo a percepção dos pescadores e ambientalistas.

Table 5. Benefits attributed to rivers by the native vegetation and reforestation according to perception of fishermen and environmentalists.

\begin{tabular}{lcccccc}
\hline \multicolumn{1}{c}{ Benefícios } & \multicolumn{2}{c}{$\begin{array}{c}\text { Pescadores } \\
(\boldsymbol{\%})\end{array}$} & & \multicolumn{2}{c}{$\begin{array}{c}\text { Ambientalistas } \\
(\boldsymbol{\%})\end{array}$} \\
\cline { 2 - 3 } \cline { 5 - 6 } & MU & RFCC & & MU & RFCC \\
\hline $\begin{array}{l}\text { Abrigo para organismos } \\
\text { aquáticos }\end{array}$ & 100 & 0 & & 90 & 10 \\
$\begin{array}{l}\text { Comida para organismos } \\
\text { aquáticos }\end{array}$ & 100 & 0 & & 100 & 0 \\
$\begin{array}{l}\text { Retenção de resíduos no } \\
\text { solo marginal }\end{array}$ & 90 & 10 & & 80 & 20 \\
$\begin{array}{l}\text { Proteção contra a erosão } \\
\text { do solo da margem }\end{array}$ & 100 & 0 & & 100 & 0 \\
\hline
\end{tabular}

vegetação ciliar nativa ou reflorestada, pois "o alimento preferido dos peixes são os frutos da mata".

Foi comum entre os entrevistados a afirmação de que, para a preservação do rio e a manutenção do volume da coluna d'água do seu curso, é essencial que se mantenha a integridade das nascentes, entendida como a preservação da mata ciliar e do solo sob a vegetação.

O papel da mata ciliar na preservação da integridade ambiental dos rios Santana e São Francisco, em Lagoa da Prata, foi reconhecido por ambos os grupos e evidenciado em suas afirmações, na maioria das vezes, em consonância com o conhecimento científico sobre o tema (Tabela 6).

\section{Discussão}

O grupo dos pescadores foi formado por indivíduos de baixo nível escolar, incluindo-se entre eles até analfabetos. Entretanto, o percentual de analfabetos que ele conteve foi menor que a média (16\%) proposta pelo senso demográfico do Instituto Brasileiro de Geografia e Estatística (Brasil 2000) para os moradores de Lagoa da Prata com idade entre 45 a 60 anos, na qual se inseriu a maioria do grupo. No estado de Minas Gerais o percentual de analfabetos é ainda maior, sendo que em indivíduos cuja idade varia de 40 a 60 anos ele corresponde a $19 \%$ da população (Brasil 2000).

O nível de escolaridade dos pescadores refletiu a realidade do ensino no Brasil. Até a primeira metade do século XX, o número de escolas do país era reduzido e o acesso à educação era restrito aos centros urbanos. A partir da década de 40 esta realidade começou a mudar com a implantação do plano nacional de erradicação do analfabetismo, pelo governo federal, em 1946. Esta época inaugurou a fase de expansão da escola básica regular no país, inclusive no meio rural (Barbosa 1994). Desde então, a educação passou por um processo intenso e progressivo de democratização e a escola começou a receber um maior e mais diversificado número de alunos (Soares 2003). Este conjunto de situações explica o desnível de escolaridade dos grupos amostrados. Por ser composto por indivíduos mais jovens, nascidos em sua maioria nas cidades após a década de 50, os ambientalistas 
Tabela 6. Cognição comparada sobre a importância das matas ciliares para a preservação do ambiente aquático em Lagoa da Prata, na região do Alto São Francisco.

Table 6. Cognition compared on the importance of riparian zones to preserve the aquatic environment in Lagoa da Prata, in the region of the Upper San Francisco.

Conhecimento Empírico

Conhecimento Científico

“...a mata ciliar protege a barranca "...a cobertura vegetal das margens é de extrema importância para a sua preservação, pois evita do rio." a erosão dos solos adjacentes..." (Barrela et al. 2000)

“... a mata ciliar dá a temperatura certa "A presença da vegetação diminui a penetração da luz solar e a ação dos ventos amortecendo as para a água." variações de temperatura da água...” (Barrela et al. 2000)

“... a mata ciliar dá alimento para os “...pode-se observar a utilização de frutos, folhas e flores como alimento de várias espécies de peixes." peixes" (Barrela et al. 2000)

“... a mata ciliar segura a água no "As matas ciliares representam excelentes locais de armazenamento de água visando garantia de solo."

66...a mata faz voltar as águas." suprimento contínuo” (Bren 1993)

“...a vegetação ciliar contribui para o aumento da capacidade de armazenamento da água na microbacia ao longo da zona ripária, o que contribui para o aumento da vazão na estação seca do ano" (Elmore \& Beschta 1987)

“.. a mata ciliar aduba o solo." "A serapilheira representa a principal via de retorno de nutrientes e matéria orgânica à superfície do solo mineral que sustenta a floresta" (Durigan et al. 1995)

puderam freqüentar regularmente escolas, com níveis progressivos de ensino regular. Situação oposta foi vivenciada pelos indivíduos que formaram o grupo dos pescadores. Por ser representado por homens mais velhos, nascidos antes do plano de erradicação do analfabetismo, eles não puderam se beneficiar desta situação, tendo que buscar na pesca, profissão que aprenderam com seus antepassados, a opção financeira para sua sobrevivência.

O número de filhos dos grupos amostrados reflete indiretamente seu nível de escolaridade. Enquanto os pescadores tiveram proles mais numerosas formadas por 5, 6 ou mais filhos, os ambientalistas se restringiram a um ou dois filhos, ou mesmo a nenhum deles. Em grupos com baixo nível de escolaridade, as famílias são formadas, geralmente, por proles mais numerosas, com 4 filhos em média, como o registrado por Thé (1998) para as famílias de pescadores profissionais artesanais de um segmento do rio São Francisco, localizado no município de Três Marias, ao norte de Lagoa da Prata.

Apesar de conviverem com as matas ciliares por motivos diferentes, os indivíduos de ambos os grupos as visitaram para lazer e para verificar seu estado de conservação. Durante as visitas destinadas à fiscalização, os grupos realizaram ações conservacionistas junto à vegetação orientados pelas ONGs locais. Além disso, os ambientalistas as visitaram também para "catalogar espécies vegetais", destinadas a serem utilizadas nos replantios de matas ciliares da região, e "realizar estudos em grupos nas matas", entendidos por eles como o reconhecimento das espécies nativas que caracterizam a vegetação.

O desconhecimento dos indivíduos de ambos os grupos sobre as dimensões do Reflorestamento, necessárias à proteção do rio Santana contra a erosão do solo da margem e o assoreamento do leito do rio, se confirmou ao se contrapor suas informações com o proposto no Código Florestal de Minas Gerais (Lei n ${ }^{\circ}$ 4.777/65), que determina para rios com menos de $10 \mathrm{~m}$ de largura, como o Rio Santana, uma faixa de vegetação ciliar de $30 \mathrm{~m}$ em ambas as margens. Apesar de não fazer referência ao comprimento das matas ciliares, a legislação estadual determina que elas se estendam ao longo de todo o curso do rio, o que, entretanto, não se verificou no Reflorestamento desde a época de sua implantação. Ao se constituir em um fragmento isolado, ele não apresentou processo de continuidade com o remanescente da vegetação ciliar nativa ainda presente ao longo da margem do rio.

Embora desconhecessem as dimensões do reflorestamento, foi unânime, por parte dos grupos, a informação de que seu plantio feito a uma distância muito grande em relação à margem do rio, deixando a descoberto uma faixa do solo que acabou sendo ocupada por gramíneas capazes de competirem e de impedirem a instalação no local das espécies arbóreas nativas ou implantadas. Para Martins (2001), em locais onde a vegetação ciliar foi implantada distante do curso d'água, o solo desnudo tende a ser colonizado por espécies invasoras, como gramíneas exóticas, capazes de competirem e inibirem a regeneração natural das espécies arbóreas nativas, como também observado no Reflorestamento. Sob tais condições, o autor recomenda o controle das populações invasoras e o estímulo da regeneração natural das espécies nativas.

Ao afirmarem que o Reflorestamento "não foi plantado com as espécies corretas" porque não eram as nativas do lugar, pescadores e ambientalistas apresentaram conhecimento que coincidiu com o citado na literatura científica. No grupo dos ambientalistas o conhecimento sobre o tema pode ter sido adquirido nas escolas, mas, sobretudo, pelas atividades desenvolvidas por eles junto às ONGs ambientalistas de Lagoa da Prata. Para os pescadores, o conhecimento decorreu particularmente de seu convívio cotidiano com o ambiente ribeirinho. De acordo com Hanazaki (2004), um conhecimento etnobotânico detalhado é revelado na relação entre pescadores e recursos vegetais, seja com relação aos recursos utilizados na cultura material do grupo, ou através da sua relação histórica com atividades agrícolas de subsistência, como obtenção de alimentos e remédios. Com frequência, este conhecimento vai além das espécies em particular, refletindo também um amplo conhecimento sobre as formações florestais e os processos dos ecossistemas.

O conhecimento local sobre a sazonalidade da produção e o destino da serapilheira da mata nativa foi parcialmente compatível com o científico, construído, em parte, pelo convívio que os entrevistados mantiveram com este tipo de ambiente ao longo dos anos. Entretanto, tal fato não se verificou em relação ao reflorestamento, o que poderia ser atribuído ao convívio esporádico, mantido por motivo profissional ou lazer. Os indivíduos de ambos os grupos não o visitam, nem pescam neste trecho do rio Santana, devido ao seu aspecto pouco atraente (baixo nível da água, lixo urbano nas margens, composição florística da vegetação marginal) e ao avançado estado de assoreamento do seu leito, o que, em conjunto, determina a pobreza em número, tamanho e em espécies da ictiofauna, assim como a desconfiguração da paisagem natural no local (Nunes 2005). Segundo Barreto (2002), o Reflorestamento foi implementado às margens do rio Santana com 
espécies disponíveis nos viveiros florestais da Prefeitura Municipal de Lagoa da Prata e do entorno, nos quais, de modo geral, a maioria das espécies não era nativa das matas ciliares da região.

Embora desconhecessem a dinâmica de funcionamento de ambas as matas, ao citarem os benefícios ambientais prestados por elas, tais como "adubar o solo", "segurar a água no solo", "evitar erosão" e "ajudar a fazer chover", os grupos revelaram um conhecimento sobre as funções exercidas pela vegetação ribeirinha para a manutenção da integridade ambiental dos rios, condizente com o apresentado pelas pesquisas científicas sobre o tema, como citado por Barrela et al. (2000), Kageyama \& Gandara, (2000) e Martins (2001). Para estes autores, a mata ciliar exerce funções importantes na conservação dos ecossistemas aquáticos, tais como proteção da margem do rio contra processos erosivos, regulação da temperatura da lâmina d'água através do sombreamento pelas copas das árvores, fornecimento de alimento e abrigo aos organismos aquáticos, entre outros. A importância do Reflorestamento para a preservação do solo ribeirinho, expressa por meio de afirmações do tipo "ele é um pouco pior que a mata", poderia estar associada ao estágio sucessional em que ele se encontra. Apesar de o plantio ter ocorrido há aproximadamente 20 anos e ser o mais antigo do município de Lagoa da Prata, ainda hoje se encontra em fase inicial de sucessão ecológica, o que foi reconhecido por parte dos entrevistados por meio da expressão: "com o tempo, ele fica bom igual à mata nativa".

As percepções demonstradas por ambos os grupos revelaram o alto nível de importância que atribuíram à vegetação ciliar, nativa e reflorestada, para a manutenção da integridade ambiental dos ecossistemas aquáticos do qual fazem parte. Embora o conhecimento dos ambientalistas estivesse relacionado às ações das ONGs locais, acrescidas das atividades executadas nas escolas sobre o tema, a dos pescadores refletiram, sobretudo, as orientações recebidas das organizações não governamentais, que são instituições locais que atuam na promoção da educação ambiental dos pescadores, realizando palestras e seminários, como presenciado diversas vezes no local durante a realização deste estudo.

O histórico da ocupação das margens do rio São Francisco e tributários pelos pescadores da região de Lagoa da Prata demonstra que, inicialmente, eles se relacionavam com o rio de forma a somente se beneficiarem da pesca e do espaço de lazer que delimitavam nos seus "ranchos", habitação rústica que ocupavam nestes locais. A percepção da importância da mata ciliar nativa e reflorestada para a conservação do rio e manutenção da oferta do pescado faz parte de um conhecimento recente, especialmente incentivado pelos programas de educação ambiental implementados pelas ONGs da região. Tal fato se confirma pela observação de ranchos mais antigos, localizados ao longo do rio São Francisco e Santana, onde um grande número de espécies frutíferas plantadas no local para o consumo dos seus proprietários recobre áreas anteriormente ocupadas pelas espécies nativas do ambiente ciliar. Remanescentes deste tipo de paisagem ainda hoje são encontrados na região.

Os plantios de espécies nativas para a recuperação da vegetação ribeirinha remontam ao início da década de 80 e demonstram a preocupação dos diferentes segmentos sociais da população com a recuperação do ambiente ribeirinho. Tal fato evidencia o sucesso das ações das ONGs ambientalistas locais, que iniciaram suas atividades nesse período com a realização de projetos de educação ambiental destinados à conservação e recuperação deste trecho da bacia em Lagoa da Prata e entorno. Desde então, este tipo de ação vem sendo desenvolvido junto às escolas, através de cursos de treinamento e palestras para professores, aulas e visitas de campo com os alunos, parcerias feitas com as colônias de pescadores profissionais para execução de serviço de manutenção da região ribeirinha dos rios locais, além de feiras, gincanas e mutirões para a coleta de sementes das espécies nativas e o plantio de mudas de árvores, envolvendo toda a comunidade.

O conhecimento demonstrado pelos pescadores e ambientalistas de Lagoa da Prata sobre o papel da vegetação ciliar para a manutenção da integridade ambiental dos ecossistemas aquáticos, respaldado na literatura técnico-científica, confirmou a importância de se considerar o saber de grupos sociais locais nos processos de manejo e conservação das matas ciliares, de forma a permitir a construção de estratégias conservacionistas inclusivas. Essa visão encontra respaldo em Sachs (1993), para quem os procedimentos desenvolvimentistas têm que levar em conta a relação homem-planta-animal, uma vez que as populações humanas locais detêm conhecimento sobre os ecossistemas com os quais convivem.

O conhecimento dos pescadores e ambientalistas sobre a estrutura física e a dinâmica de funcionamento das matas ciliares nativa e implantada do município de Lagoa da Prata decorreu de seu contato com as mesmas, motivado por ações de subsistência (pesca), lazer ou para realizar atividades conservacionistas orientadas pelas ONGs ambientalistas locais. A atuação das ONGs ambientalistas junto aos dois grupos teve papel decisivo na construção do seu saber sobre a importância da preservação e recuperação da vegetação ciliar para a manutenção da qualidade ambiental do rio São Francisco e tributários, no trajeto de seu curso pelo Alto São Francisco.

Embora com perfis sociais distintos, especialmente em relação à idade e ao nível de escolaridade, os pescadores e ambientalistas avaliados no presente estudo revelaram-se uma fonte importante de informações para a elaboração de planos de manejo e conservação dos ecossistemas ribeirinhos locais, assim como para o aprimoramento das estratégias de recuperação da vegetação ciliar na região, ao demonstrarem um conhecimento sobre o tema, muitas vezes equivalente ao citado na literatura científica.

\section{Referências Bibliográficas}

AMOROZO, M.C.M. \& GÉLY, A. 1988. Uso de plantas medicinais por caboclos do baixo Amazonas, Barcarena, PA, Brasil. Boletim do Museu Paraense Emílio Goeldi, Série Botânica 4(1):47-131.

BARBOSA, J.J. 1994. Alfabetização e leitura. Cortez, São Paulo.

BARBOSA, L.M. 2000. Considerações gerais e modelos de recuperação de formações ciliares. In Matas ciliares: Conservação e recuperação (R.R. Rodrigues \& HF Leitão-Filho eds). EDUSP/FAPESP, São Paulo, p. 289-312.

BARRELA, W., PETRERE, M., WELBER, S.S. \& ASSIS MONTAG, L. 2000. As relações entre as Matas ciliares, os rios e os peixes. In Matas ciliares: Conservação e recuperação (R.R. Rodrigues, H.F. Leitão-Filho eds). EDUSP/FAPESP, São Paulo, p. 187-208.

BARRETO, G.F. 2002. A avifauna como indicadora de qualidade de reflorestamento ciliar no Alto São Francisco (Lagoa da Prata, MG). Dissertação de Mestrado. Pontifícia Universidade Católica de Minas Gerais. Belo Horizonte.

BEGOSSI, A., CASTRO, F. \& SILVANO, M. 2004. Ecologia humana e conservação. In Ecologia de pescadores da Mata Atlântica e da Amazônia (A. Begossi ed). HUCITEC, São Paulo, p. 313-324.

BRASIL. Instituto Brasileiro de Geografia e Estatística. 1975. Carta do Brasil. Folha de Bom Despacho. IBGE, Rio de Janeiro.

BRASIL. Instituto Brasileiro de Geografia e Estatística. 2000. Censo de população de 2000. IBGE, Rio de Janeiro.

BREN, L.L. 1993. Riparian Zone, Stream and Floodplain Issues: A Review. Journal of Hydrology, 150:277-299.

CETEC/Fundação Centro Tecnológico de Minas Gerais. 1983. Diagnóstico Ambiental do estado de Minas Gerais. Série de Publicações Técnicas/ SPT 10. IGA/Secretaria de Ciências e Tecnologia/MG, Belo Horizonte. 
DURIGAN, G., LEITÃO-FILHO, H.F. \& PAGANO, S.N. 1995. Produção de serapilheira em matas ciliares na região oeste do estado de São Paulo. Revista do Instituto Florestal 9(7):197-239.

ELMORE, W. \& BESCHTA, R.L. 1987. Riparian areas: Perceptions in management. Rangelands 9(6):260-265.

GLADWIN, C. 1989. Etnographic decision tree modeling. Qualitative Research Methods. Sage Publication, Thousand Oaks/CA.

GOOLEY, F.B., MACGINNIS, J.T., CLEMENTES, R.G., CHILD, G.I. \& DUEVER, M.J. 1978. Ciclagem de minerais em um ecossistema de floresta tropical úmida. EDUSP, São Paulo.

GORGÔNIO, A.S. 1998. Estudo ambiental de alterações antrópicas nas matas de galeria da bacia hidrográfica do ribeirão Taboca (APA do Rio São Bartolomeu- Distrito Federal). Série Meio Ambiente. IBAMA, Brasília.

HANAZAKI, N. 2004. Etnobotânica. In Ecologia de pescadores da Mata Atlântica e da Amazônia (A. Begossi ed). HUCITEC, São Paulo, p. 37-57.

HENRY, R. 2003. Ecótonos nas interfaces dos ecossistemas aquáticos. Ed. RiMa, São Carlos.

KAGEYAMA, P. \& GANDARA, F.B. 2000. Recuperação de áreas degradadas. In Matas ciliares: Conservação e recuperação (R.R. Rodrigues \& H.F. Leitão Filho eds). EDUSP/FAPESP, São Paulo, p. 249-270.

LE SANN, J.G. 2002. Atlas escolar de Lagoa da Prata. Prefeitura Municipal de Lagoa da Prata, Belo Horizonte.
LIMA, W.P. 2003. Relações hidrológicas em matas ciliares. In Ecótonos nas interfaces dos ecossistemas aquáticos (R. Henry ed). Editora RiMa, São Carlos, p. 293-300.

MARTINS, S.V. 2001. Recuperação de matas ciliares. Aprenda Fácil, Viçosa.

MITSCH, W.J. \& GOSSELINK, J.G. 1986. Wetlands. Van Nostrand Reinhold, New York.

NUNES, F.P. 2005. O homem, as matas ciliares e os peixes de Lagoa da Prata, no alto São Francisco: Um estudo das interrelações. Dissertação de Mestrado. Pontifícia Universidade Católica de Minas Gerais, Belo Horizonte.

RICHARDSON, R.J. 1999. Pesquisa social: Métodos e técnicas. Atlas, São Paulo.

SACHS, I. 1993. Estratégias de transição para o século XXI. Nobel/FUNDAP, São Paulo.

SOARES, M. 2003. Alfabetização e letramento. Contexto, São Paulo.

THÉ, A.P.G. 1998. Etnoecologia e produção pesqueira dos pescadores da represa de Três Marias (MG). Dissertação de Mestrado. Universidade Federal de São Carlos, São Carlos.

VIERTLER, R.B. 2002. Métodos antropológicos como ferramenta para estudos em etnobiologia e etnoecologia. In Métodos de coleta e análise de dados em etnobiologia e etnoecologia e disciplinas correlatas (M.C.M Amorozo, L.C. Ming \& S.P. Silva eds). CNPQ-UNESP, Rio Claro, p. 11-29. 
